Vol. 39(2), pp. 213-226, Dec. 2020

ISSN 1821-536X (print)

ISSN 2619-8789 (electronic)
Tanzania Journal of Engineering and Technology

Copyright () 2020 College of Engineering and

Technology, University of Dar es Salaam

Full Length Research Paper

\title{
Analysis of Performance Characteristics Predicted From Several Experimental Data and Conversion Methods for Pumps as Turbine Application Using Statistical Techniques
}

\author{
Ombeni J. Mdee ${ }^{1 *}$, Cuthbert Z. M. Kimambo², Torbjorn K. Nielsen ${ }^{3}$, Joseph Kihedu ${ }^{2}$ \\ ${ }^{1}$ Department of Petroleum and Energy Engineering, University of Dodoma, Tanzania. \\ ${ }^{2}$ Department of Mechanical and Industrial Engineering, University of Dar es Salaam, \\ Tanzania. \\ ${ }^{3}$ Department of Energy and Process Engineering, Norwegian University of Science and \\ Technology, Norway. \\ *Corresponding author: ombenijohn@gmail.com
}

\begin{abstract}
Different performance characteristics have been indicated when running centrifugal pumps in the reverse direction. The water flows from the discharge side of the pump to the suction side to run in the reverse direction and generate the mechanical rotational energy for the micro-hydropower plant. The current study evaluates the extent of variation of performance characteristics predicted by several experimental data from different pump-specific speeds and conversion methods. The performance characteristics discussed include the head, flow rate, efficiency and specific speed. The flow rate and head of a pump operating in pump mode divided with the characteristic of the pump operating in the reverse mode, at the best efficiency point, the resulting coefficient of determination $\left(R^{2}\right)$ values were of 0.890 and 0.708 , respectively. Also, the graph of head versus flow rate coefficients, which is a secondorder polynomial function, has shown the value of $R^{2}$ of 0.954 for pump-specific speed ranging between 9 and $94 \mathrm{rpm}$. However, the pump in the reverse mode has smaller performance characteristics for efficiency and specific speed compared to the pump mode operation with $R^{2}$ of 0.966 and 0.999 , respectively. Furthermore, schematic empirical statistical models were developed to predict the performance characteristics of several conversion methods using pump data obtained from the manufacturers.
\end{abstract}

Keywords: Conversion method, pump as turbine, performance characteristics, statistical techniques.

\section{INTRODUCTION}

The selection of a centrifugal pump to operate as turbine at a given specific speed needs the conversion of flow rate and head. Fortunately, experimental and numerical studies have indicated the possibility of a centrifugal pump to run in the reverse direction without any technical complications (Dribssa et al., 2015; Patel et al. 2015; Singh et al. 2013; Nautiyal et al., 2011; Fernández et al., 2009; Derakhshan and Nourbakhsh, 2008a; Rawal and Kshirsagar, 2007). The modification of pump components in the volute-casing, radial clearance zone, 
impeller size, suction eye and draft tube can only slightly increase the efficiency (Derakhshan and Kasaeian, 2014; Singh, 2005). However, these modifications are not feasible in small hydropower schemes, due to limitations in the ability to modify the pump components or making an order directly to the manufacturer that would increase the adjustment cost (AlatorreFrenk, 1994). Also, conventional water turbines such as the Pelton, Francis and Kaplan turbines are expensive in terms of uniqueness per specific site associated with the needs of high experiences, skills and knowledge. This hinders their utilization in small hydropower development (Muttalli et al., 2014; Kaunda et al., 2012; Aggidis et al., 2010). Centrifugal pumps are commonly used in water pumping for domestic, industrial, irrigation, livestock and sewage systems (Muttalli et al., 2014). Also, the centrifugal pumps are available in less than $100 \mathrm{~kW}$ capacities that limits the capacities of its application in micro-hydropower (Fernández et al., 2004; Williams, 1995).

The centrifugal pumps are rated with heads, flow rates and power supplied at the Best Efficiency Point (BEP). Manufacturers do not provide the performance characteristics of their application in reverse mode. Experimental evidence indicates that centrifugal pumps operate at higher heads and flow rates in the reverse (turbine) mode than in pump mode at the same rotational speed (Derakhshan et al., 2009; Derakhshan and Nourbakhsh, 2008a; Williams, 1995). Existing conversion methods have been used to convert the pump characteristics to the turbine mode characteristics (AlatorreFrenk, 1994; Williams, 1994). The conversion methods are used to convert the performance characteristic parameter such as head, flow rate, efficiency and specific speed. However, each conversion method predicts different values of head, flow rate, specific speed and efficiency from one pump to another. Therefore, the current study determines the extent of variation using statistical techniques for different characteristics predicted by several conversion methods.

\section{HISTORICAL DEVELOPMENT OF CONVERSION METHODS}

Barbarelli et al. (2017) developed a conversion method with geometric dimension variables to determine the Pump as Turbine (PAT) characteristics. The conversion method is based on the relationship of the four equations related to pump specific speed as follows: (i) Head shut-off for the different number of blades and blade angles (ii) Flow rate coefficient for different number of blades (iii) Volutevelocity coefficient and (iv) Pump diameter ratio variation. Huang et al (2017) developed the rotor-volute matching principle based on pump Euler's equation and velocity relationships to predict the PAT characteristics. The rotorvolute matching principle worked without using performance datasheet from pump manufacturers. Li (2017) indicated the effects of converting the pump head, flow rate and efficiency to turbine mode by using the Reynolds number (NRe). An impeller with the Reynolds Number reference of $8,295,768$ was used to develop the conversion ratios for head, flow rate and efficiency as presented in equation (1). 


$$
\left.\begin{array}{c}
q=1.5144-1.0557 * 10^{-3}\left(\frac{N_{e}}{N_{e f}}\right)^{-1.35} \\
h=1.50 .32-1.4343 * 10^{-1}\left(\frac{N R_{e}}{N R_{e f}}\right)^{-0.25} \\
\eta=0.9065-4.8354 * 10^{-2}\left(\frac{N R_{e}}{N_{e f}}\right)^{-0.25} \\
\text { But } N_{e}=\frac{n^{2} p}{\mu}
\end{array}\right\}
$$

This conversion method predicts the head, flow rate and efficiency ratios with errors of $1.67 \%, 2.57 \%$ and $6.76 \%$, respectively. The symbol $h, q, \eta, \rho, \mu$ and $D$ represent the head ratio, flow rate ratio, efficiency, density of water, viscosity of water and impeller outlet diameter. Nielsen (2015) derived an equation governing the pump in turbine mode of operation using Euler's equation and pump geometry parameters. Nautiyal et al. (2011) developed the head ratio and flow rate ratio by using regression analysis as presented in equation (2).

$$
\mathrm{q}=30.303 \chi-3.424 \text { and } \mathrm{h}=41.667 \chi-5.042 \text {, but } \chi=\frac{\eta_{\mathrm{gp}}-0.212}{\operatorname{lnn}_{\mathrm{sp}}}
$$

The term " $\chi$ " in equation (2) is related to efficiency and specific speed $\left(n_{s}\right)$ in rpm, and is used to give the regression analysis of head and flow rate ratios. Derakhshan and Nourbakhsh (2008b) developed a conversion method for head and flow rate by using experimental data and specific speed formula as presented in equation (3).

$\mathbf{h}=\frac{\mathrm{n}_{\mathrm{t}} / \mathrm{n}_{\mathrm{p}}}{0.0233 \frac{\mathrm{n}_{\mathrm{sp}}}{\mathrm{g}^{0.75}}+0.6464}$ and $\mathrm{Q}_{\mathrm{p}}=\left(\frac{\mathrm{n}_{\mathrm{sp}}}{\mathrm{n}_{\mathrm{p}}}\right)^{2}\left(\frac{\mathrm{H}_{\mathrm{t}}}{\mathrm{h}}\right)^{1.5}$

The symbol $n, H, Q$ and $g$ represent the speed of rotation in rpm, head in $\mathrm{m}$, flow rate in $\mathrm{m}^{3} / \mathrm{s}$ and gravitation acceleration in $\mathrm{m} / \mathrm{s}^{2}$ respectively. Subscripts $t$ and $p$ denote the turbine mode and pump mode operations respectively. Chapallaz et al. (1992) developed curves for head ratio and flow rate ratio versus pump specific speed as presented in Figures 1 and 2, using the datasheet provided by pump manufacturers. This gives the PAT- specific speed equal to pump specific speed times a constant factor of 0.89 . The low specific speeds of 10 to $20 \mathrm{rpm}$ have a head ratio greater than 1.65 and efficiency from $70 \%$ to $55 \%$, while the flow rate ratio is greater than 1.4. The high specific speed of greater than $30 \mathrm{rpm}$ has lower ratios of head and flow rate of 1.65 and 1.4 respectively, with efficiency greater than $70 \%$. The minimum value of head ratio is 1.25 and flow rate ratio is 1.2 . 


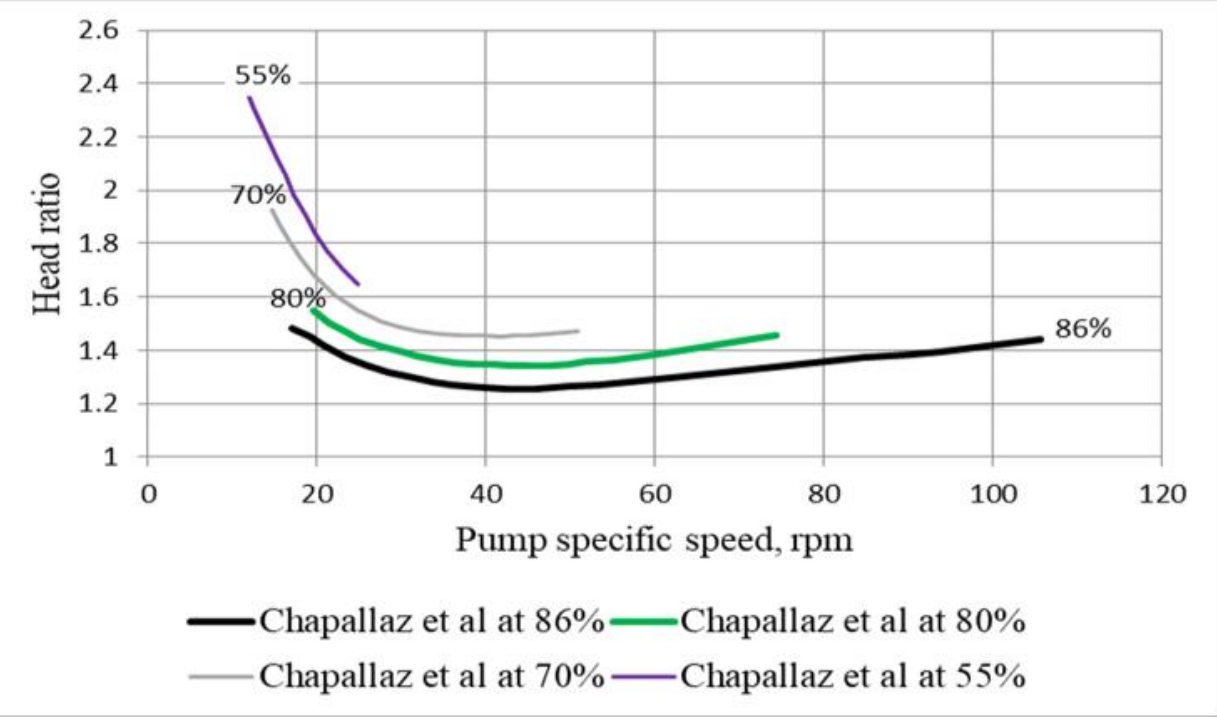

Figure 1: Head ratio versus pumps specific speed with different efficiency curves (Chapallaz et al., 1992)

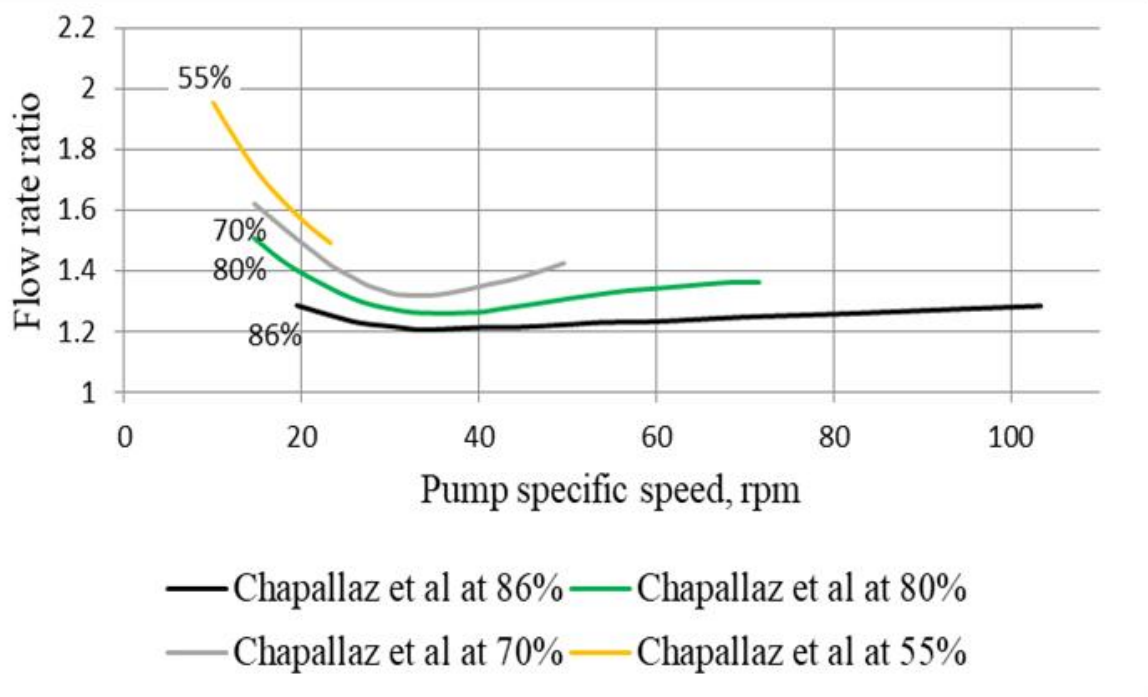

Figure 2: Flow rate ratio versus the pumps specific speed with different efficiency curves (Chapallaz et al., 1992)

\section{MATERIALS AND METHODS}

The characteristic curves of head, flow rate and efficiency for pump running in the reverse direction or turbine mode and pump mode operation are shown in Figure 3. At the maximum efficiency, it is possible to locate the head and flow rate for pump running in the turbine mode and pump mode. The head ratio and flow rate ratio are expressed in equation (4) at a given BEP. Also, considering the same
BEPs in turbine mode and pump mode, we expect that $\mathrm{h}=1, \mathrm{q}=1$; but a pump running in turbine mode operates away from the pump BEP, with higher head and flow rate. This makes the idea to develop the conversion methods to predict the performance characteristics be based on the four main parameters, which are the head, flow rate, specific speed and efficiency.

$\mathrm{h}=\frac{\mathrm{H}_{\mathrm{t}}}{\mathrm{H}_{\mathrm{p}}}$ and $\mathrm{q}=\frac{\mathrm{Q}_{\mathrm{t}}}{\mathrm{Q}_{\mathrm{p}}}$ 


\section{Data Collection}

The conversion methods for head ratio and flow rate ratio are shown in Table 1. The conversion methods consist of the input variables such as pump efficiency, specific speed and speed of rotation. In this study, only the conversion methods with an input variable of pump efficiency were selected to determine the extent of variation of head ratio and flow rate ratio. Efficiency data was taken ranging between 0.1 and 1 , as the global range of the mechanical machine efficiency. Table 2 consists of literature sourced data of head, flow rate and efficiency collected from different pumps. The pumps used have the specific speed range from 9 to $94 \mathrm{rpm}$ $\left(\mathrm{n}_{\mathrm{s}}=\mathrm{nQ}^{0.5} / \mathrm{H}^{0.75}\right)$.

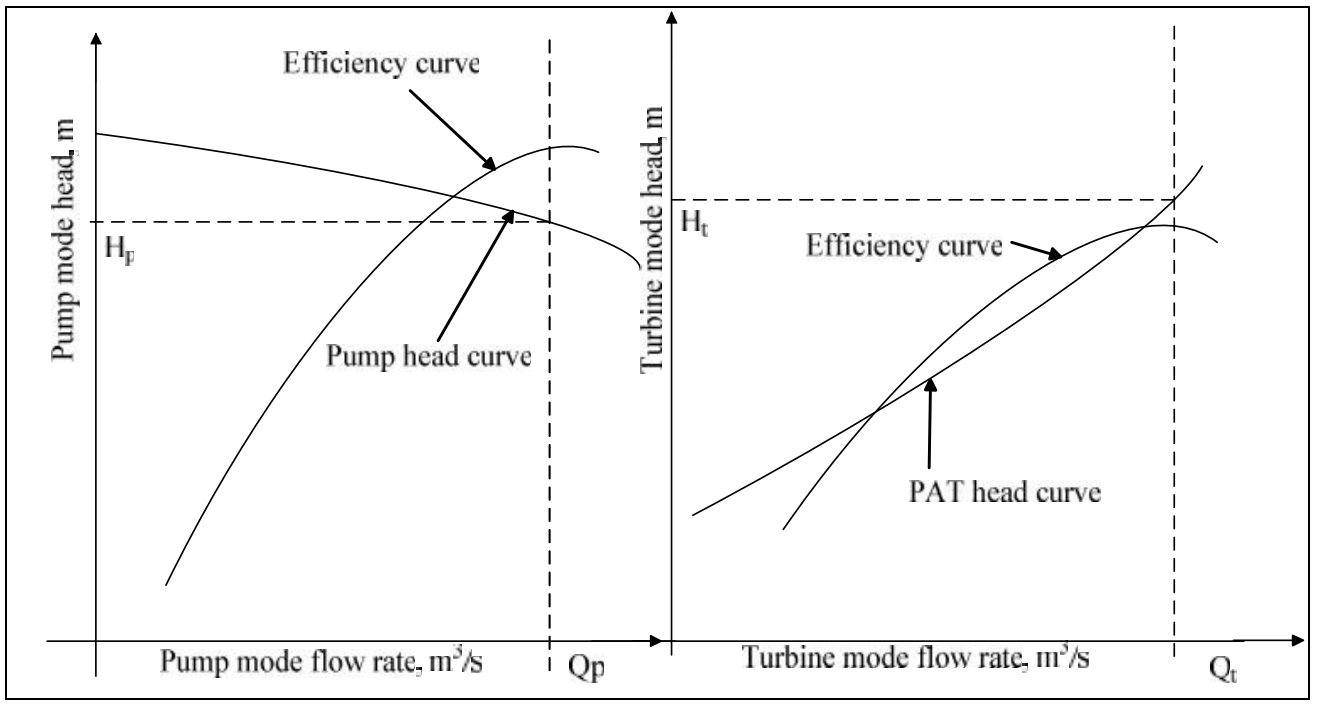

Figure 3: Schematic diagram of head and efficiency versus flow rate for different pumps in pump and turbine modes

\section{Data Analysis}

The non-dimensional head coefficient $(\phi)$ and flow rate coefficient $(\varphi)$ were used to characterize the head versus flow rate relationship. The non-dimensional coefficients are presented in equations (5). The characteristic curves for the different pumps, as indicated in Table 2, were developed in terms of non-dimensional coefficients. The curves of head against flow rate coefficients were digitized and combined from different literature sources for analyzing the general performance characteristics.

The methods presented in Table 1 were used to analyze the extent of variation for head, flow rate, efficiency and specific speed. The characteristic curves and conversion methods provide data that was used in the linear regression analysis. The linear regression analysis of using the coefficient of determination $\left(R^{2}\right)$ that measures the fitness of turbine mode characteristics from pump mode characteristics was used. This linear regression analysis helps to determine the extent of variation for head, flow rate, efficiency and specific speed by developing empirical statistical models. After regression analysis, $R^{2}$, which is a number ranging between 0 and 1 is obtained. A value of $R^{2}$ closer to 1 signifies a good degree of fitness, as described by Campbell and Campbell (2008).

$\Phi=\frac{\mathrm{g} * \mathrm{H}}{\mathrm{n}^{2} \mathrm{D}^{2}}$ and $\varphi=\frac{\mathrm{Q}}{\mathrm{n}^{*} \mathrm{D}^{3}}$ 
Table 1: Conversion methods for head ratio and flow rate ratio

\begin{tabular}{|l|l|l|}
\hline Head ratio & Flow rate ratio & Names of investigators \\
\hline $\mathrm{h}=\frac{1}{\eta_{\mathrm{p}}}$ & $\mathrm{q}=\frac{1}{\eta_{\mathrm{p}}^{0.5}}$ & Stepanoff \\
\hline $\mathrm{h}=\frac{1}{\eta_{\mathrm{p}}^{1.2}}$ & $\mathrm{q}=\frac{1}{\eta_{\mathrm{p}}{ }^{0.8}}$ & Sharma \\
\hline $\mathrm{h}=\frac{1}{\eta_{\mathrm{p}}}$ & $\mathrm{q}=\frac{1}{\eta_{\mathrm{p}}}$ & Childs \\
\hline $\mathrm{h}=\frac{1}{0.85 \eta_{\mathrm{p}}{ }^{5}+0.385}$ & $\mathrm{q}=\frac{0.85 \eta_{\mathrm{p}}{ }^{5}+0.385}{2 \eta_{\mathrm{p}}{ }^{9.5}+0.205}$ & Alatorre-Frenk \\
\hline $\mathrm{h}=\frac{1}{\eta_{\mathrm{p}}}$ & $\mathrm{q}=\frac{1}{\eta_{\mathrm{p}}{ }^{2}}$ & Gopalakrishnan \\
\hline $\mathrm{h}=1.56$ & $\mathrm{q}=1.40$ & Alatorre-Frenk 1 \\
\hline $\mathrm{h}=1.30$ & $\mathrm{q}=1.35$ & Sanchez \\
\hline $\mathrm{h}=1.471$ & $\mathrm{q}=1.471$ & Palgrave \\
\hline $\mathrm{h}=1.556 \mathrm{n}_{\mathrm{sp}}^{-0.174}$ & $\mathrm{q}=1.402 \mathrm{n}_{\mathrm{sp}}^{-0.171}$ & Diederich \\
\hline $\mathrm{h}=\left(\frac{\mathrm{n}_{\mathrm{t}}}{\mathrm{n}_{\mathrm{p}}}\right)^{2} \frac{1}{\eta_{\mathrm{p}}^{1.2}}$ & $\mathrm{q}=\left(\frac{\mathrm{n}_{\mathrm{t}}}{\mathrm{n}_{\mathrm{p}}}\right) \frac{1}{\eta_{\mathrm{p}}{ }^{0.8}}$ & Williams \\
\hline $\mathrm{h}=1.21 \eta_{\mathrm{p}}^{-0.8}\left[1+\left(0.6+\ln \mathrm{n}_{\mathrm{sp}}\right)^{2}\right]^{0.3}$ & $\mathrm{q}=1.21 \eta_{\mathrm{p}}{ }^{-0.6}$ & Alatorre-Frenk \\
\hline
\end{tabular}

The values of $h$ and $q$ for any pump are calculated by inputting the pump efficiency and specific speed into the respective equations. Table 3 shows the conversion equations used to relate the efficiency of pump running in turbine mode to that of the pump mode. Table 4 shows the specific speed conversion equations. The specific speed is the parameter used to describe the uniqueness of geometrical shapes of different pumps.

Table 2: Summary of data used to analyze the PAT characteristics

\begin{tabular}{|c|c|c|c|c|}
\hline Source & Singh (2005) & $\begin{array}{l}\text { Derakhshan and } \\
\text { Nourbakhsh } \\
\text { (2008a) }\end{array}$ & $\begin{array}{l}\text { Tan and } \\
\text { Engeda (2016) }\end{array}$ & $\begin{array}{l}\text { Barbarelli et } \\
\text { al. (2017) }\end{array}$ \\
\hline $\begin{array}{lr}\text { Pumps } & \text { with } \\
\text { different } & \text { specific } \\
\text { speeds }(\mathrm{rpm}) \text { tested }\end{array}$ & $\begin{array}{c}21,24.5,35.3, \\
36.4,39.7,45.2, \\
46.4,61.3,72.8, \\
79.1 \text { and } 94.4\end{array}$ & $\begin{array}{c}14.6,23 \\
37.6 \text { and } 55.6\end{array}$ & $\begin{array}{l}30.7,43.7 \\
63.5 \text { and } 80.5\end{array}$ & $\begin{array}{c}9.08,12.8, \\
28.7,30.31, \\
34.11 \text { and } \\
64.07\end{array}$ \\
\hline Head coefficient & $\sqrt{ }$ & $\sqrt{ }$ & $\sqrt{ }$ & $\sqrt{ }$ \\
\hline $\begin{array}{ll}\text { Flow } & \text { rate } \\
\text { coefficient }\end{array}$ & $\sqrt{ }$ & $\sqrt{ }$ & $\sqrt{ }$ & $\sqrt{ }$ \\
\hline Efficiency & $\sqrt{ }$ & $\sqrt{ }$ & $\sqrt{ }$ & $\sqrt{ }$ \\
\hline $\begin{array}{l}\text { Number of pumps } \\
\text { tested }\end{array}$ & 11 & 4 & 4 & 6 \\
\hline
\end{tabular}


Table 3: Efficiency relations of running pump in turbine mode and pump mode

\begin{tabular}{|c|l|l|}
\hline S/N & Turbine mode efficiency & Source \\
\hline 1 & $\eta_{\mathrm{t}}=\eta_{\mathrm{p}}(0.75-0.8)$ & Krivichenko (1994) \\
\hline 2 & $\eta_{\mathrm{t}}=\eta_{\mathrm{p}}-0.03$ & Chapallaz et al. (1992) \\
\hline 3 & $\begin{array}{l}\eta_{\mathrm{t}}=\eta_{\mathrm{p}} *\left(0.893+0.0466 \mathrm{n}_{\mathrm{sp}}\right) ; \\
\text { Valid for } 0.2 \leq \mathrm{n}_{\mathrm{sp}} \geq 1.1\end{array}$ & \multirow{2}{*}{ Alatorre-Frenk (1994) } \\
\hline 4 & $\eta_{\mathrm{t}}=\eta_{\mathrm{p}} *(0.92-0.99)$ & \\
\hline 5 & $\eta_{\mathrm{t}}= \pm 0.02 * \eta_{\mathrm{p}}$ & \\
\hline 6 & $\eta_{\mathrm{t}}=\eta_{\mathrm{p}}$ & \\
\hline
\end{tabular}

Table 4: Specific speed relations of running pump in turbine mode and pump mode

\begin{tabular}{|l|l|l|l|}
\hline \multirow{2}{*}{$\mathrm{S} / \mathrm{N}$} & \multicolumn{2}{|c|}{ Specific speed } & Source \\
\cline { 2 - 4 } & Relationship & Range & \\
\hline 1 & $\mathrm{n}_{\mathrm{st}}=\frac{\mathrm{n}_{\mathrm{sp}}-1.7}{1.12}$ & & Yang et al. (2012) \\
\hline 2 & $\mathrm{n}_{\mathrm{st}}=0.942 \mathrm{n}_{\mathrm{sp}}-3.2$ & 20 to $80 \mathrm{rpm}$ & Singh and Nestmann (2011) \\
\hline 3 & $\mathrm{n}_{\mathrm{st}}=0.89 \mathrm{n}_{\mathrm{sp}}$ & Single stage up to $110 \mathrm{rpm}$ & Chapallaz et al. (1992) \\
\hline
\end{tabular}

\section{RESULTS AND DISCUSSION}

\section{Head and Flow Rate Coefficients}

The head and flow rate coefficients were calculated by using equation (4). Figure 4 presents the percentage of head coefficients versus flow rate coefficients $\frac{\phi}{\phi_{\max }}=0.0096\left(\frac{\varphi}{\varphi_{\max }}\right)^{2}-0.2297\left(\frac{\varphi}{\varphi_{\max }}\right)+25.836$

for 25 pumps of specific speed ranging between 9.08 and $94.4 \mathrm{rpm}$. The percentage variation of head or flow is equal to the head or flow rate divided by the maximum of its value. The conversion methods of head versus flow rate are expressed in equation (6) with the polynomial order of two and $R^{2}$ of 0.954 .

\section{PAT Efficiency}

The PAT efficiency curves were generated using the data presented in Table 2. This includes pump of specific speed of $18 \mathrm{rpm}$ (Nautiyal et al., 2011), $70 \mathrm{rpm}$ (Couzinet et al., 2013) and $93.2 \mathrm{rpm}$ (Qian et al., 2016). Figure 5 shows the PAT efficiency versus the percentage flow for different pumps. The PAT operation mode attained an efficiency of higher than $70 \%$ for high specific speed pumps of greater than 50 rpm. Low specific speed pumps attained lower efficiency of less than $70 \%$. The PAT efficiency curve started when the percentage flow rate rangingfrom $40 \%$ and $50 \%$ for many pumps when running in the reverse direction.

\section{Head Characteristics by Using Conversion Methods}

The head ratio was estimated using six (6) conversion methods from Appendix, Table 1. The conversion methods of Stepanoff, Sharma, Childs and Gopalakrishnan were used to predict the head ratio. The head ratio decreased with increasing pump efficiency (Figure 6). The conversion methods' predictions came closer to each 
other when the efficiency was higher than 0.4. The head ratio data from six conversion methods versus efficiency were fitted in the different trendlines of logarithmic, polynomial, power and linear function as expressed in equations (7). The head ratio versus the efficiency data ranging from 0.4 to 1 with logarithmic function has been higher with the $R^{2}$ of 0.890 compared to polynomial, power or linear functions.

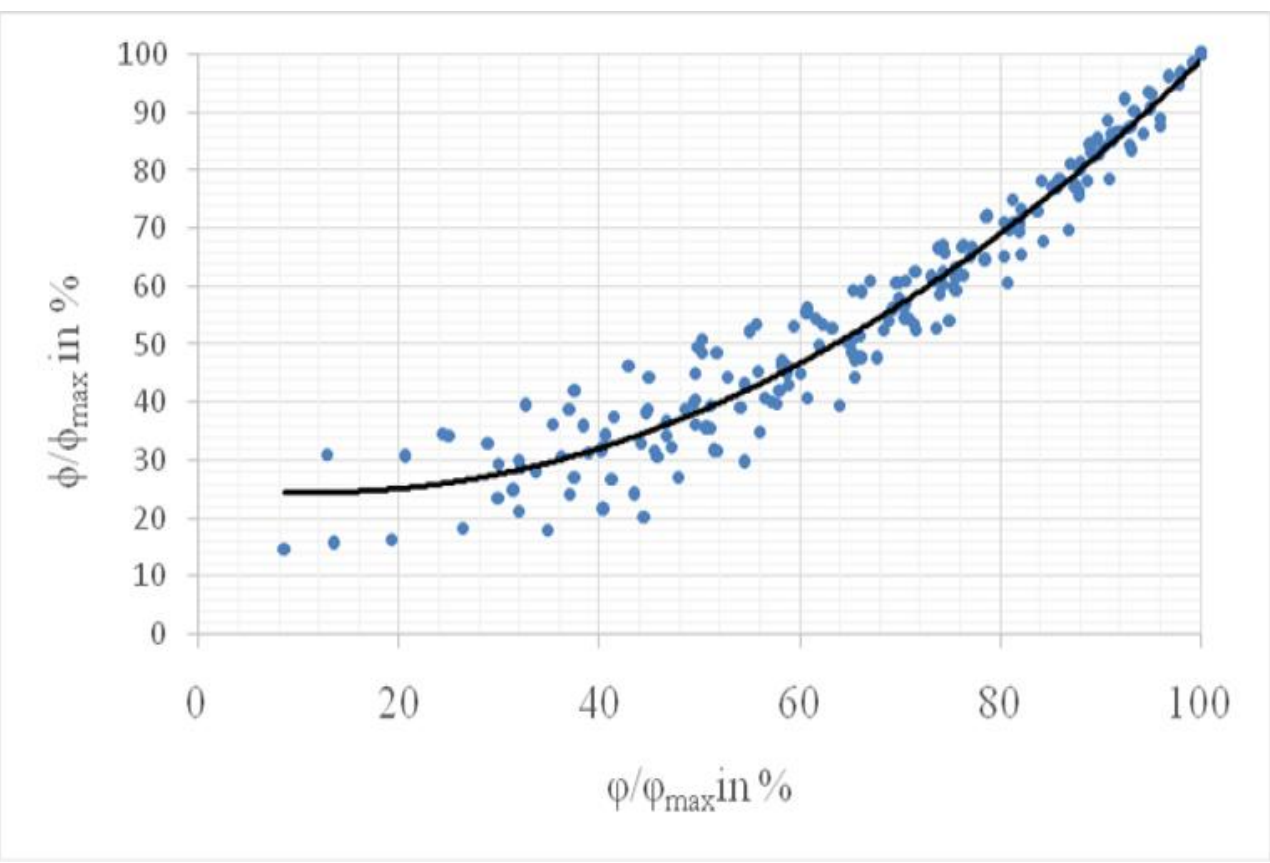

Figure 4: Percentage variation of head with flow coefficients for different pumps

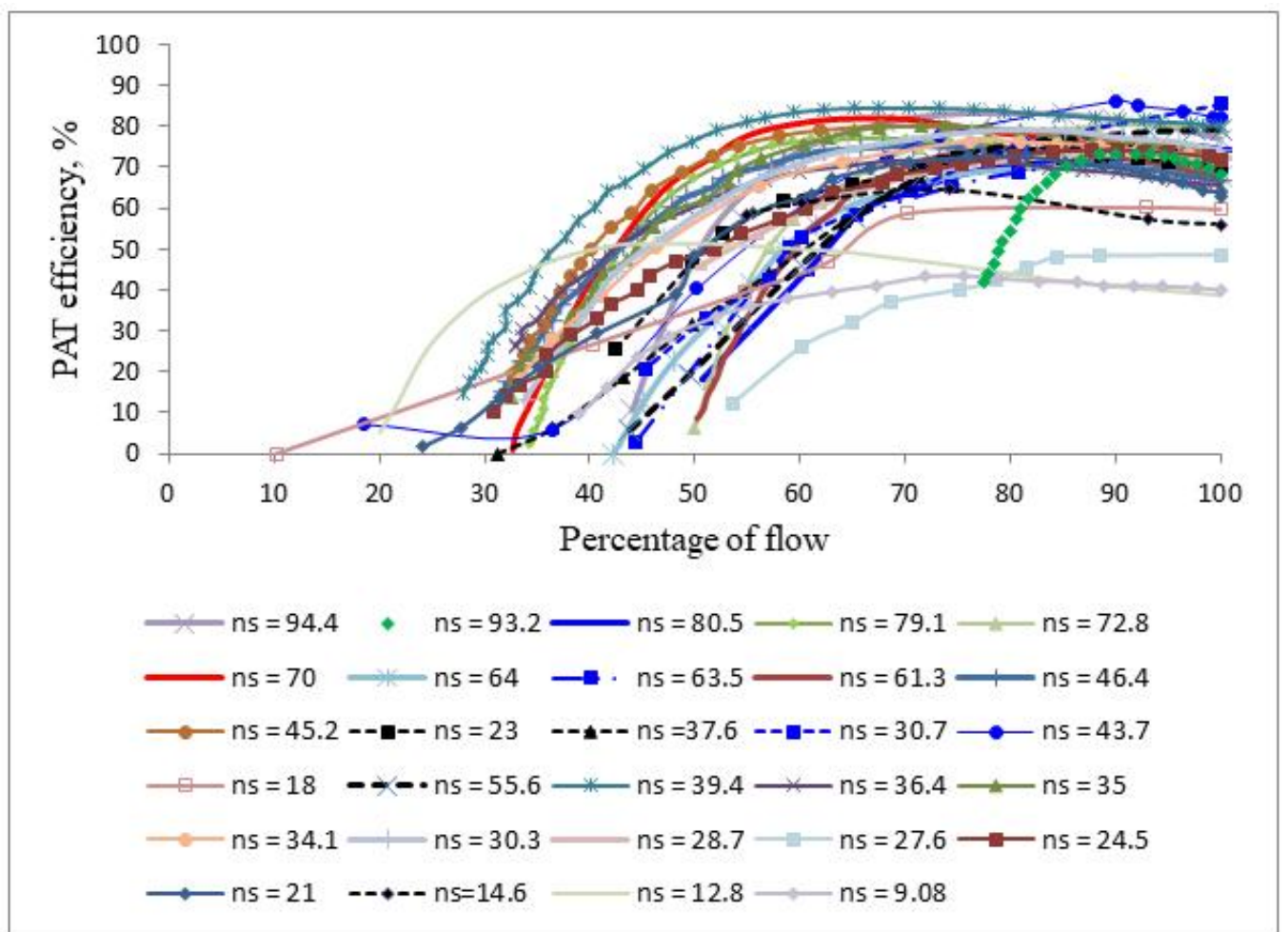

Figure 5: Variation of PAT efficiency with percentage of flow for different pumps 


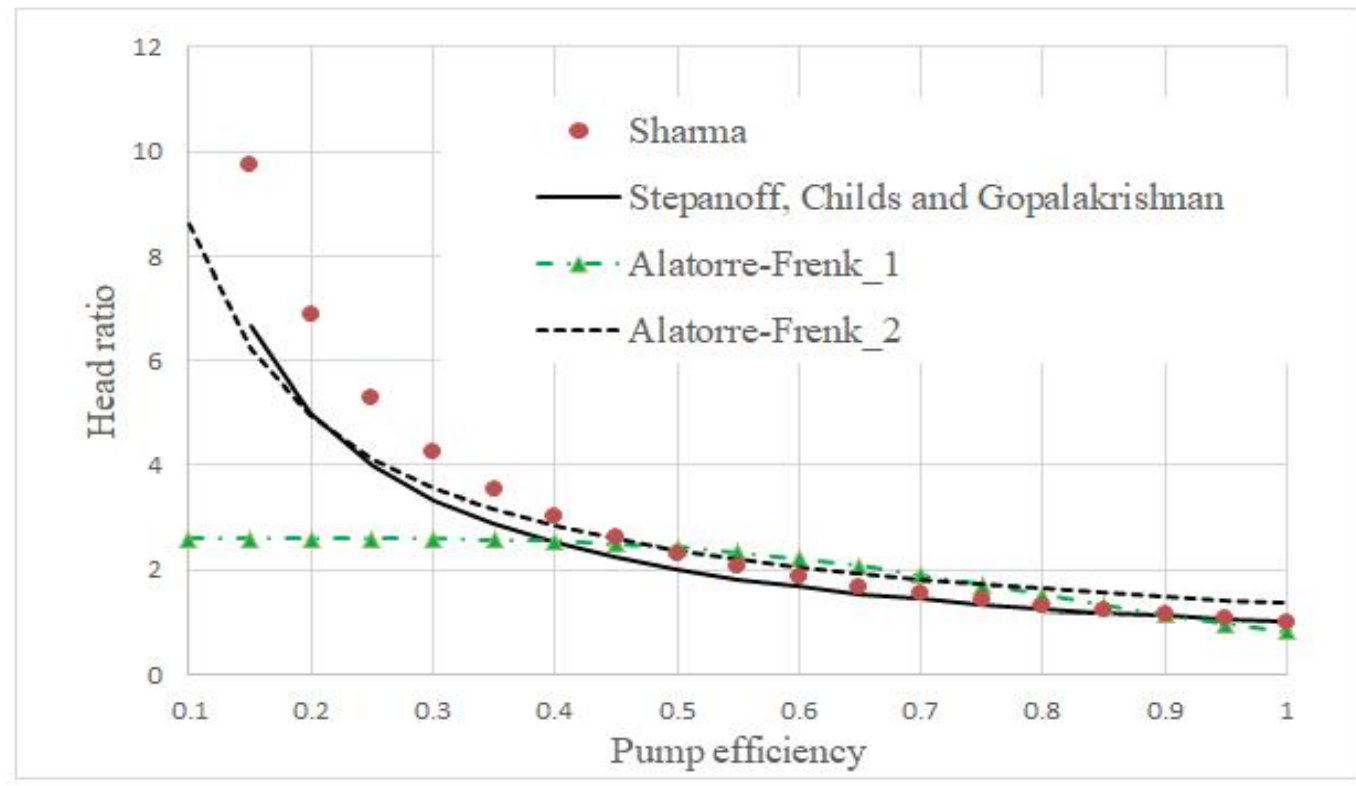

Figure 6: Variation of head ratio with pumps efficiency

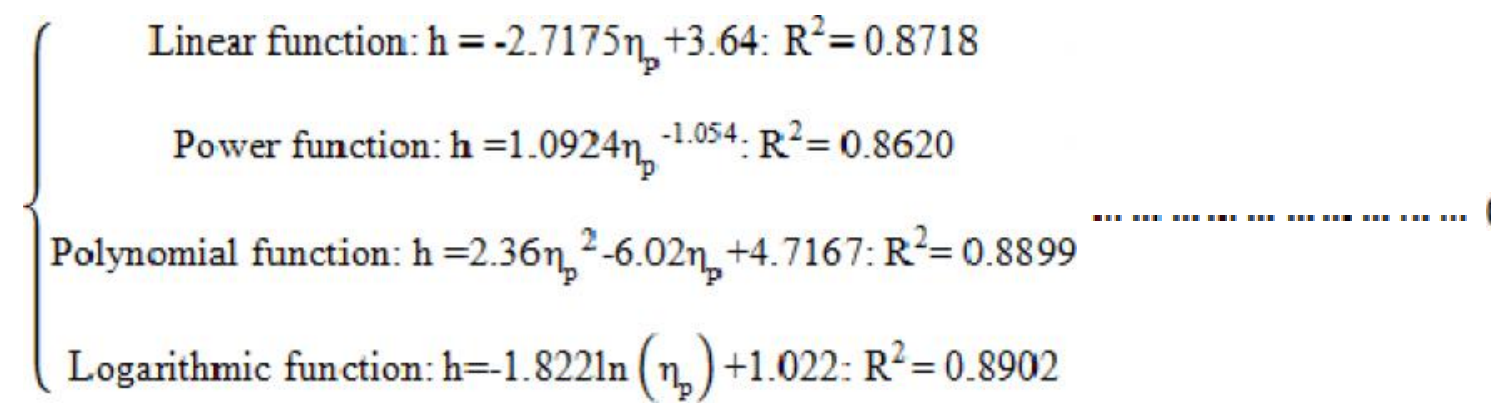

\section{Flow Rate Characteristic by Using Conversion Methods}

The flow rate ratio was estimated by using six (6) conversion methods from Table 1. The flow rate ratio decreased as pump efficiency increases (Figure 7). The Gopalakrishnan conversion method gave flow rate ratio exceeding 0.75 . This is on the higher side compared to the flow rate ratio obtained using other five conversion methods. This scenario suggests it is reasonable to compare the other five conversion methods with different trendlines of logarithmic, polynomial, power and linear functions as expressed in equations (8). The flow rate ratio versus efficiency data that are ranging from 0.4 to 1 exhibited polynomial relation with $R^{2}$ of
0.708 , i.e., the squared $R$ is higher compared to the logarithmic, power or linear functions.

\section{Efficiency Characteristic by Using Conversion Methods}

The PAT efficiency was calculated by using the relationship presented in the Table 3 and pump efficiency ranging between 0.1 and 1 . The PAT efficiency increased with pump efficiency as shown in Figure 8. The PAT efficiency lied below the $45^{\circ}$ line, indicating it to be lower than the pump efficiency. The efficiency relationships from six conversion methods fitted with the $R^{2}$ value of 0.966 . 


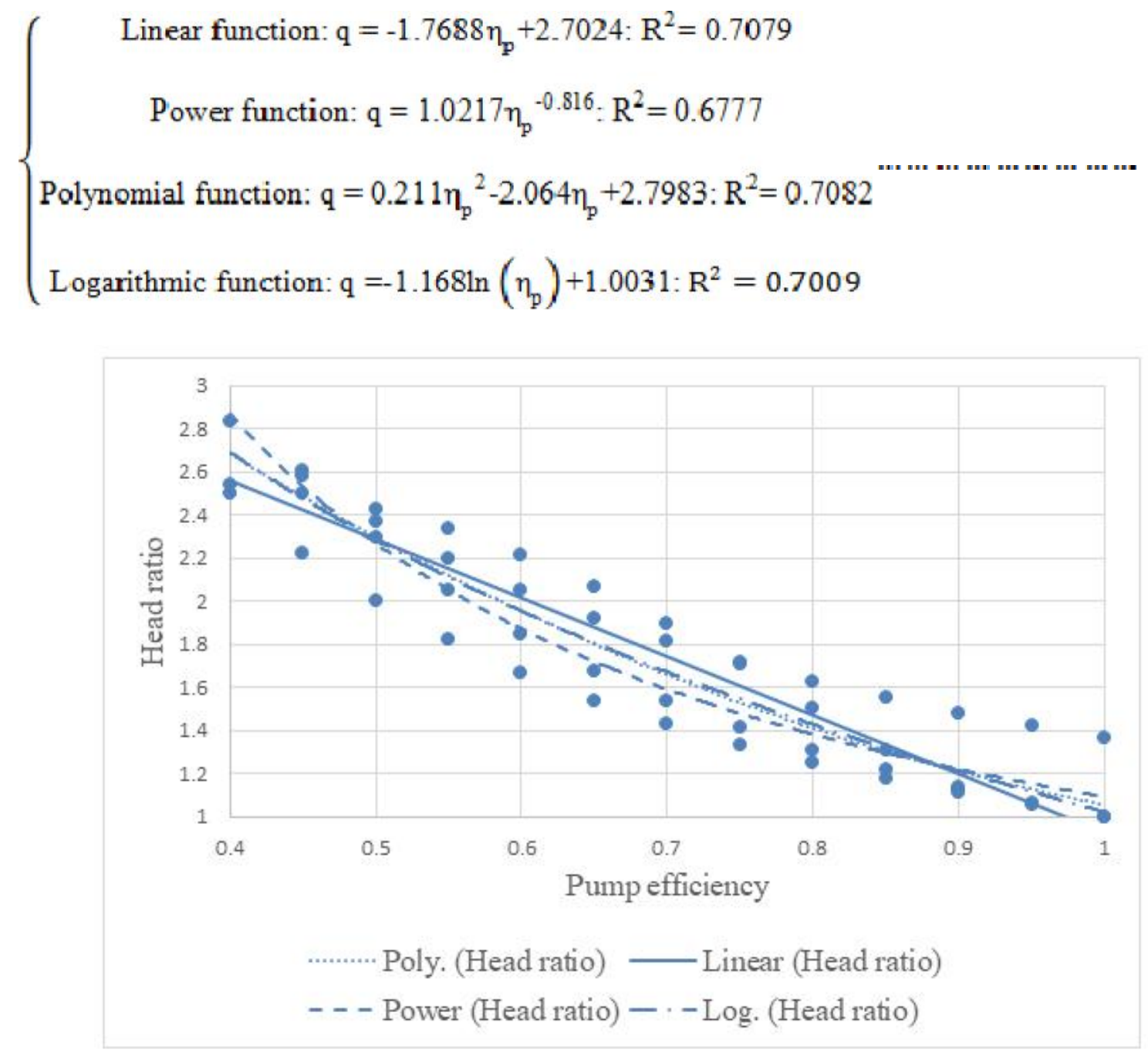

Figure 7: Variation of flow rate ratio with pumps efficiency

\section{Specific Speed Characteristic by Using Conversion Methods}

The PAT specific speed was calculated by using the relationships shown in Table 4 and pump specific speed ranging between 9.08 and $94 \mathrm{rpm}$. The PAT specific speed increased with pump specific speed as shown in Figure 9. The PAT specific speed is lower than the pump specific speed with the best fit line lying below the $45^{\circ}$ line. The specific speed relationships from three conversion methods fitted with the $R^{2}$ value of 0.999 .

\section{DISCUSSION}

The head characteristic variable is higher in turbine mode compared to the pump mode operation. The pump in turbine mode runs on either left or right side of the flow rate design point i.e. at the BEP. PATs have lower efficiency and specific speed than those of pump mode operation. Statistical analysis was summarized by developing the schematic diagram, Figure 10. This shows stepwise procedures of converting the performance characteristics of centrifugal pumps to PAT operation mode. The conversion methods for predicting efficiency were applied to estimate the head ratio. The pump head is 
estimated by using the PAT head. The specific speed model can be applied to estimate the pump flow rate for a known speed of rotation. It can also be used to estimate PAT flow rate for a particular hydropower site. The conversion methods for flow rate can be used to determine the PAT flow that should be equal to the flow from the proposed hydropower site.

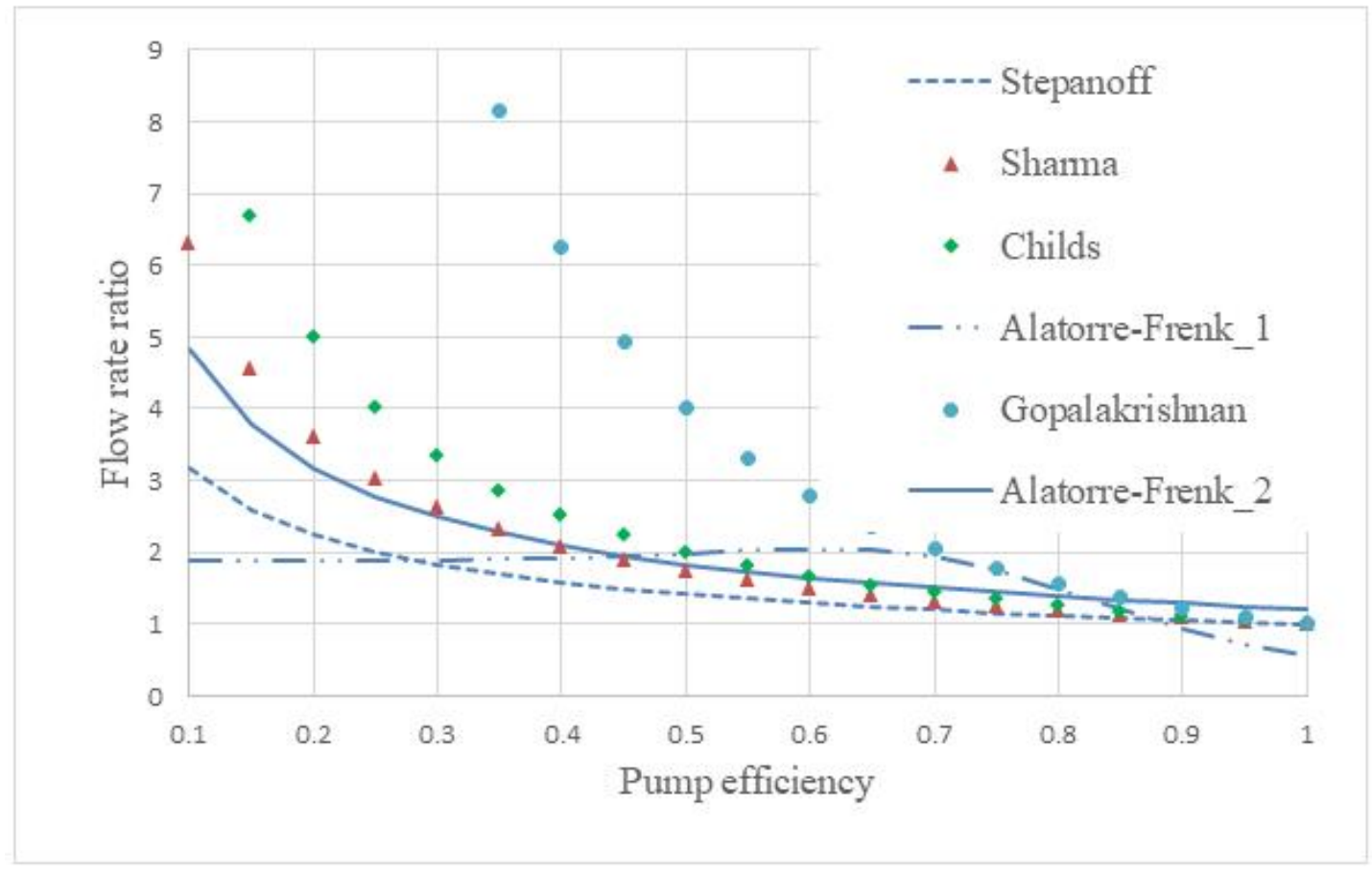

Figure 8: Variation of PAT efficiency with pump efficiency

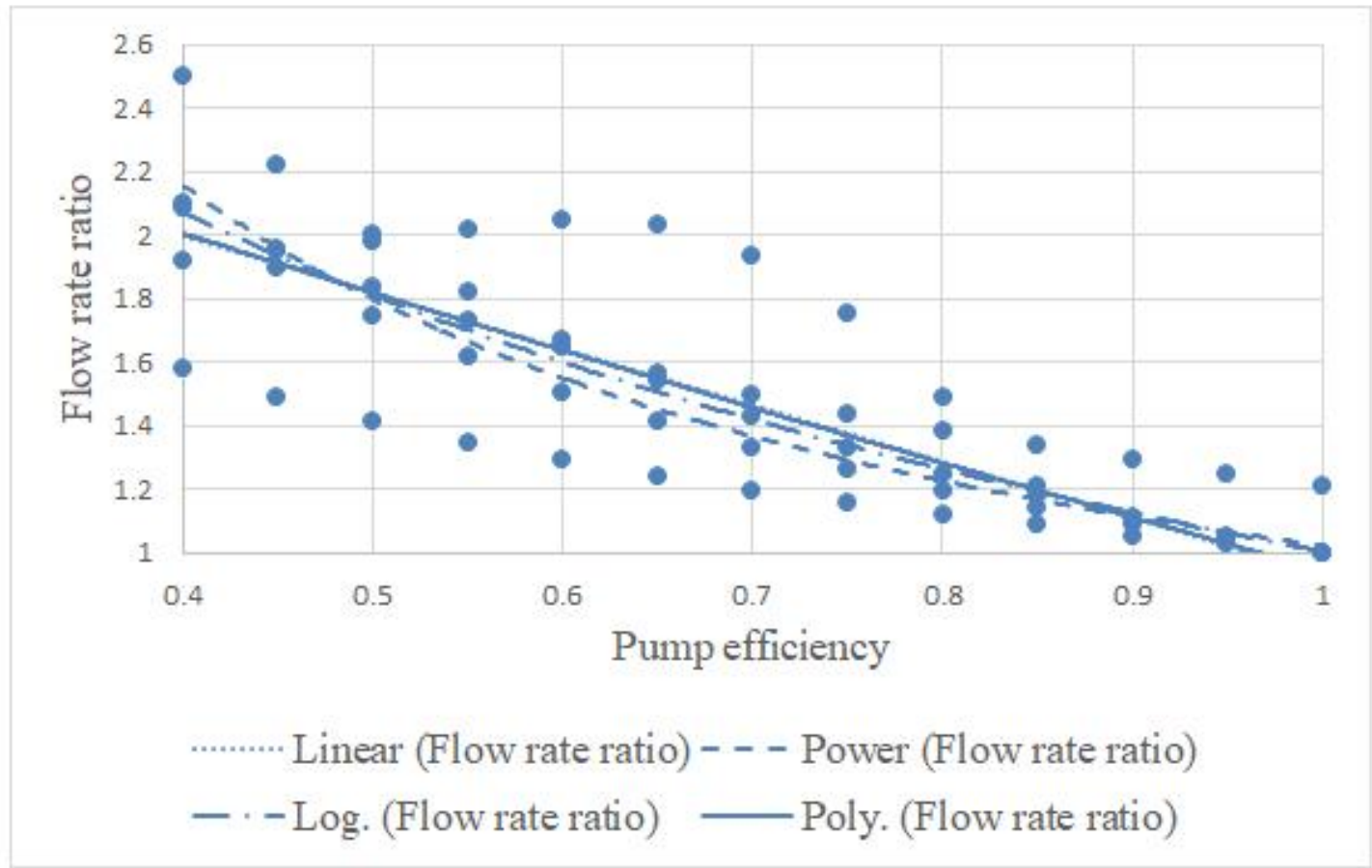

Figure 9: Variation of PAT specific speed versus pump specific speed 


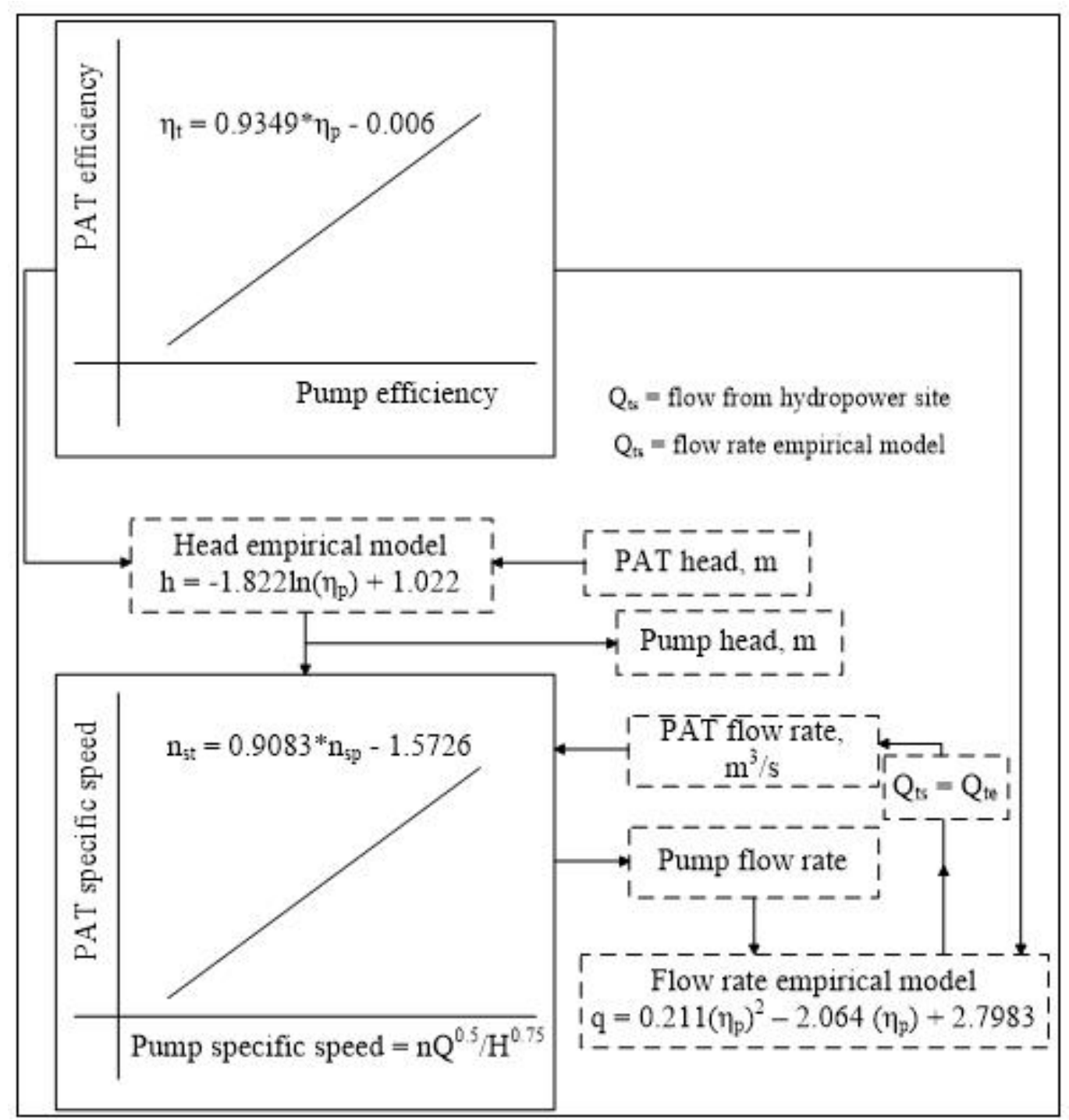

Figure 10: Schematic of the empirical models for converting the centrifugal pump characteristics in the reverse mode of operation

\section{CONCLUSIONS}

The general performance characteristic curves of head coefficient and efficiency against flow rate coefficient have been developed for pumps running in the turbine mode of operation. The statistical models were developed from the curves and proposed a schematic model for selecting centrifugal pumps for hydropower plants. However, the experimental data collected after digitized curves from different literature sources indicated the following: (i) head coefficient against flow rate coefficient best fitted with the polynomial of the order of two, and (ii) each centrifugal pump has different trend lines against the percentage of flow rate. PAT operates with the percentage of flow rate greater than $20 \%$.

The study also used six conversion methods and secondary data to statistically analyze the performance characteristic of PAT and indicated the following: $(i)$ head ratio against pump efficiency fitted well with the logarithmic function of base 10 , (ii) flow rate ratio against pump efficiency fitted well with the polynomial order of two, (iii) PAT efficiency is lower than the pump efficiency by the empirical equation, i.e., $\eta_{\mathrm{t}}=0.9349^{*} \eta_{\mathrm{p}}-0.006$; (iv) PAT specific speed is lower than the pump specific speed by the empirical equation, 
i.e., $\eta_{t}=0.9349^{*} \eta_{p}-0.006$. Therefore, this study indicates the head, flow rate, efficiency and specific speed varied differently when analyzed with the statistical techniques.

\section{ACKNOWLEDGEMENTS}

This work was supported financially by the Norwegian Agency for Development Cooperation (Norad) under its Energy and Petroleum (EnPe) Programme at the University of Dar es Salaam (UDSM), Tanzania and the Norwegian University of Science and Technology (NTNU), Trondheim, Norway.

\section{REFERENCES}

Aggidis G.A., Luchinskaya E., Rothschild R. and Howard D. C. (2010). The Costs of Small-Scale Hydro Power Production: Impact on the Development of Existing Potential. Renewable Energy, 35: 2632-2638. DOI: 10.1016/j.renene.2010.04.008.

Alatorre-Frenk C. (1994). Cost Minimisation in Micro Hydro Systems Using Pumps-As-Turbines. Coventry, United Kingdom. PhD Thesis, Department of Engineering, University of Warwick, UK. Available at http://go.warwick.ac.uk/wrap/36099:

Barbarelli S., Amelio M. and Florio G. (2017). Experimental Activity at Test Rig Validating Correlations to Select Pumps Running as Turbines in Microhydro Plants. Energy Conversion and Management, 149: 781-797. DOI: 10.1016/j.egypro. 2017.08.282.

Chapallaz J.M., Eichenberger P. and Fischer G. (1992). Manual on Pumps Used as Turbines. Vieweg, Braunschweig: Printed in the Federal Republic of Germany by Lengericher Handelsdruckerei, Lengerich.

Campbell D. and Campbell S. (2008). Introduction to Regression and Data Analysis. In StatLab Workshop Series.
Derakhshan S. and Kasaeian N. (2014). Optimization, Numerical and Experimental Study of a Propeller Pump as Turbine. Journal of Energy Resources Technology, 136: 1-7. DOI: 10.1115/1.4026312.

Derakhshan S., Mohammadi B. and Nourbakhsh A. (2009). Efficiency Improvement of Centrifugal Reverse Pumps. Journal of Fluids Engineering, 131: 1-9. DOI: 10.1115/1.3059700.

Derakhshan S. and Nourbakhsh A. (2008a). Theoretical, Numerical and Experimental Investigation of Centrifugal Pumps in Reverse Operation. Experimental Thermal and Fluid Science, 32: 1620-1627. DOI: 10.1016/j.expthermflusci.2008.05.004

Derakhshan S. and Nourbakhsh A. (2008b). Experimental Study of Characteristic Curves of Centrifugal Pumps Working as Turbines in Different Specific Speeds. Experimental Thermal and Fluid Science, $\quad 32$ : 800-807. DOI:10.1016/j.expthermflusci.2007.10. 004.

Dribssa E., Nigussie T. and Tsegaye B. (2015). Performance Analysis of Centrifugal Pump Operating as Turbine for Identified Micro/Pico Hydro Site of Ethiopia. International Journal of Engineering Research and General Science, 3(3): 6-19.

Fernández J., Barrio R., Blanco E., Parrondo J.L. and Marcos A. (2009). Numerical Investigation of a Centrifugal Pump Running in Reverse Mode. Proceedings of the Institution of Mechanical Engineers. Part A. Journal of Power and Energy, 224: 373-381. DOI: 10.1243/09576509JPE757.

Fernández J., Blanco E., Parrondo J., Stickland M.T. and Scanlon T.J. (2004). Performance of a Centrifugal Pump Running in Inverse Mode. Proceedings of the Institution of Mechanical Engineers, 218(4): 265-271. DOI: $10.1243 / 0957650041200632$. 
Huang S., Qiu G., Su X., Chen J. and Zou W. (2017). Performance Prediction of a Centrifugal Pump as Turbine Using Rotor-volute Matching Principle. Renewable Energy, 108: 64-71. DOI: 10.1016/j.renene.2017.02.045.

Kaunda C.S., Kimambo C.Z. and Nielsen T.K. (2012). Potential of Small-Scale Hydropower for Electricity Generation in Sub-Saharan Africa: Review Article. International Scholarly Research Network: Renewable Energy, 1-15. https://doi.org/10.5402/2012/132606

Krivichenko G. (1994). Hydraulic Machines: Turbines and Pumps. USA: Lewis, Boca Raton, Fla.

Li W. (2017). Optimising Prediction Model of Centrifugal Pump as Turbine with Viscosity Effects. Applied Mathematical Modelling, 41: 375-398. DOI: 10.1016/j.apm.2016.09.002.

Muttalli R.S., Agrawal S. and Warudkar H. (2014). CFD Simulation of Centrifugal Pump Impeller Using ANSYS-CFX. International Journal of Innovative Research in Science, Engineering and Technology, 3(8): 15553-15561. DOI: 10.15680/IJIRSET.2014.0308066.

Nautiyal H., Varun V., Kumar A. and Yadav S.Y.S. (2011). Experimental Investigation of Centrifugal Pump Working as Turbine for Small Hydropower Systems. Energy Science and Technology, 1(1): 79-86. ISSN 1923-8479.

Nielsen T.K. (2015). Simulation Model for Francis and Reversible Pump Turbines. International Journal of Fluid Machinery and Systems, 8(3): 169-182, DOI: 10.5293/IJFMS.2015.8.3.169.

Patel J.B., Mevada R.N., Sardana D. and Rajput V.P. (2015). Experimental and Numerical Investigation of Centrifugal Pump Performance in Reverse Mode. International Journal of Advanced Technology in Engineering and Science, 3(1): 1066-1072.
Rawal S. and Kshirsagar J.T. (2007). Numerical Simulation on a Pump Operating in a Turbine Mode. Proceedings of the $23^{\text {rd }}$ International Pump Users Symposium, 21-27.

Singh P. and Nestmann F.A. (2011). Consolidated Model for the Turbine Operation of Centrifugal Pumps. Journal of Engineering for Gas Turbines and Power, 133: 1-9.

Singh P. (2005). Optimization of Internal Hydraulics and of System Design for Pumps as Turbines with Field Implementation and Evaluation. $\mathrm{PhD}$ Thesis, University of Karlsruhe, Germany.

Singh R., Gupta R., Singh A. and Subbarao P.M. (2013). Guided Pumpas-Turbine: Design and Development for Pico-Level Energy Generation. International Journal of Applied Research in Mechanical Engineering, 3(1): 71-76. ISSN: 2231 - 5950.

Tan X. and Engeda A. (2016). Performance of Centrifugal Pumps Running in Reverse as Turbine: Part II Systematic Specific Speed and Specific Diameter Based Performance Prediction. Renewable Energy. 99: 188197.

DOI:

10.1016/j.renene.2016.06.052.

Williams A.A. (1994). The Turbine Performance of Centrifugal Pumps: A Comparison of Prediction Methods. Proceedings of the Institution of Mechanical Engineers, Part A. Journal of Power and Energy, 208: 59-66.

Williams A. (1995). Pumps as Turbines: A User's Guide. Intermediate Technology Publications, London. ISBN: 185339 2855.

Yang S.S., Derakhshan S. and Kong F.Y. (2012). Theoretical, Numerical and Experimental Prediction of Pump as Turbine Performance. Renewable Energy, 48: 507-513. DOI: 10.1016/j.renene.2012.06.002. 